Gut, 1980, 21, 223-226

\title{
Coeliac disease associated with recurrent aphthae
}

\author{
M M FERGUSON, D WRAY, H A CARMICHAEL, R I RUSSELL, F D LEE \\ From the Department of Oral Medicine and Pathology, Dental Hospital and School, Glasgow, the \\ Gastroenterology Unit, Royal Infirmary, Glasgow, and the Department of Pathology, Royal Infirmary, Glasgow
}

SUMMARY Fifty patients presenting sequentially with a history of recurrent aphthae were investigated for evidence of nutritional deficiencies and coeliac disease. In the group, two patients were found to have coeliac disease and their recurrent aphthae cleared soon after starting a gluten free diet. This study confirms the presence of an increased prevalence of nutritional deficiency and of coeliac disease in aphthous patients. However, it is recommended that jejunal biopsy be carried out in these cases only where there is evidence of malabsorption.

Recurrent aphthae is a disorder which may have a multifactorial aetiology. Although various forms of aphthae have been described in relation to their size, distribution on the oral mucosa and duration of ulceration, these clinical criteria have not been useful in determining the aetiological factors. In an investigation of a series of patients with aphthae ${ }^{1}$ it was noted that over $17 \%$ of all cases showed nutritional deficiency, and, of these, over half responded favourably to replacement of folic acid, vitamin B12, or iron. In an age- and sex-matched group of controls, $8.5 \%$ had evidence of similar nutritional deficiencies and, hence, in those patients with recurrent aphthae who did not respond to specific replacement therapy, there appeared to be no direct relationship between the deficiency and the oral ulcers.

In the above series reported by Wray et al. ${ }^{1}(1975)$ it was found that $5 \%$ of the individuals with recurrent aphthae also had coeliac disease, this figure being considerably higher than would be expected in the general population. A subsequent study in Birmingham of 33 cases of recurrent aphthae ${ }^{2}$ reported a prevalence of $24 \%$ of coeliac disease in these patients, all cases having subtotal villous atrophy. It seemed possible, therefore, that a number of patients with recurrent aphthae associated with coeliac disease were being missed when investigations of their condition were restricted to haematological examination and jejunal biopsy was carried out only when malabsorption was suspected. Accordingly, it was decided to investigate fully a group of patients presenting sequentially to the Glasgow Dental Hospital with a history of recurrent aphthae, in order to establish the prevalence of

Received for publication 18 October 1979 coeliac disease in these patients regardless of haematological findings.

Antibodies directed to various food antigens have been reported in coeliac disease ${ }^{3}{ }^{4}$ but these also appear to occur non-specifically in relation to chronic oral ulceration. ${ }^{5}$ However, no comparison between cases of recurrent aphthae with and without associated coeliac disease has been made and the patients were screened for antibodies to cereal and animal protein antigens.

Circulating reticulin antibodies are more common in coeliac disease ${ }^{6}$ and this test was conducted in order to evaluate its usefulness in screening for coeliac disease in a group of patients with recurrent aphthae.

\section{Methods}

\section{PATIENTS}

All patients diagnosed as having recurrent aphthae using previous criteria ${ }^{1}$ were admitted to the series. The only selection of patient for this project was through their referral to the Oral Medicine Clinic by medical and dental practitioners. The study was continued until 50 patients had been fully investigated. Eighty-seven patients underwent initial screening but 37 of these were eventually discarded from the study either due to default from the Clinic or because of refusal to have a jejunal biopsy performed.

Fifty subjects completed the trial. There were 14 males and 36 females with a mean age of 30.5 years (range 13 to 60 years).

A detailed history of ulceration was obtained from each patient regarding duration, average size, precipitating factors, number per crop, mucosal distribution, time taken to heal, and time between 
crops. In addition, a general medical history was taken with particular reference being paid to alimentary and dermatological disorders.

\section{INVESTIGATIONS}

Patients with a history of recurrent oral ulceration were examined and the diagnosis of aphthae made both on the grounds of a characteristic history and on clinical examination. Venous blood was removed for the various investigative procedures and then each patient underwent jejunal biopsy. No systemic treatment was administered and an aqueous $0.2 \%$ chlorhexidine mouthwash was used for symptomatic relief until the examinations were complete.

\section{Haematology and biochemistry}

The blood was examined for haemoglobin concentration, MCV, and a film evaluated. In addition the following measurements were made: corrected whole blood folate, serum vitamin B12, serum iron and total iron binding capacity, total serum proteins and electrophoresis, albumin, calcium, and phosphate. Where a result was either abnormal or in the borderline region, the test was repeated.

\section{Gluten antibodies}

Aqueous extracts of wheat flour, oatmeal, and gluten were prepared and a microgel diffusion test $^{7}{ }^{8}$ carried out on sera.

\section{Animal protein antibodies}

Circulating antibodies were detected using precipitin tests and by passive haemagglutination. ${ }^{5}$

\section{Reticulin antibodies}

Sera were examined for the presence of antibodies (IgA) to reticulin. Using an immunofluorescent technique, titres of up to $1: 1000$ were found to be positive for rabbit kidney reticulinfibres in individuals with circulating reticulin antibodies. For the present investigation all sera were examined initially at a dilution of $1: 16$.

\section{Jejunal biopsy}

The jejunal biopsies were obtained using a CrosbyKugler capsule attached to polyvinyl tubing and passed into the jejunum under radiological screening until approximately $10 \mathrm{~cm}$ distal to the ligament of Treitz. ${ }^{9}$ The biopsies obtained were divided into two portions, one of which was immediately frozen and later analysed for disaccharidase activity (lactase, sucrase, maltase), using the method of Dahlquist. ${ }^{10}$ The other portion was histologically assessed without knowledge of the clinical or hacinatological status of the patients. Each biopsy was examined under the dissecting microscope as well as being prepared for standard histological assessment. The histological assessment included examination for significant alteration in main mucosal measurements (villus height, crypt height/villus ratio) and infiltrate. ${ }^{11}$ Significant atrophy of the mucosa was considered to be present if the villus height was less than $300 \mu$ and the crypt/villus ratio was greater than 0.6. Subjective assessment of lymphocyte content of the lamina propria and epithelial surface was also made.

\section{Results}

Of the 50 patients being fully investigated two females were eventually diagnosed as having coeliac disease. One had a six-month history of recurrent oral ulceration and the other a six-year history: their ages were 48 years and 26 years respectively. The ulcers were characteristic of minor aphthae with an average size of $5 \mathrm{~mm}$ a and typical mucosal distribution. Neither patient gave a history of dermatological disease and no cutaneous or other mucosal lesions were found. One gave a history of chronic constipation together with the production of foulsmelling stools which tended to be difficult to flush away. The final diagnosis was confirmed in these two patients by their clinical response to a gluten free diet together with replacement therapy. Repeat jejunal biopsies were performed four months after starting on a gluten free diet and the histology showed a return to normal.

The number of patients out of the 48 who had abnormal results is shown in Table 1 and the results from the two patients with coeliac disease are listed for comparison in Table 2. Of the six abnormal

Table 1 Abnormal haematological and biochemical results in 48 patients with recurrent aphthae

\begin{tabular}{lll}
\hline Investigation & $\begin{array}{l}\text { Number } \\
\text { abnormal }\end{array}$ & $\begin{array}{l}\text { Normal } \\
\text { values }\end{array}$ \\
\hline $\mathrm{Hb}$ & 5 & Males $>12 \cdot 5 \mathrm{~g} / \mathrm{dl}: \mathrm{females}>12 \cdot 0 \mathrm{~g} / \mathrm{dl}$ \\
$\mathrm{MCV}$ & 6 & $80-100 \mathrm{fl}$ \\
Film & 5 & - \\
Whole blood folate & 6 & $>100 \mathrm{ng} / \mathrm{ml}$ \\
Serum vitamin B12 & 1 & $>240 \mathrm{pg} / \mathrm{ml}$ \\
Iron saturation & 9 & $>16 \%$ \\
\hline
\end{tabular}

Table 2 Haematological and biochemical values of two patients with recurrent aphthae and coeliac disease

\begin{tabular}{lll}
\hline Test & Patient $A$ & Patient B \\
\hline $\mathrm{Hb}$ & $11 \cdot 2$ & $11 \cdot 1$ \\
$\mathrm{MCV}$ & 104 & 97 \\
Film & Macrocytic & Normal \\
Whole blood folate & 64 & 58 \\
Serum vitamin B12 & 380 & 430 \\
Iron saturation (\%) & 52 & 7 \\
\hline
\end{tabular}


MCV values in the non-coeliac patients, three were associated with iron deficiency and one with folate deficiency. Two patients had a combined iron and folate deficiency; therefore the total number with a deficiency was 14 . Of these 14 patients with a deficiency, only five had an abnormal haemoglobin or MCV. The haematological values of the 37 patients not biopsied were comparable with the 50 and did not show any significant difference.

Antibodies to an aqueous extract of wheat flour, oatmeal, or gluten were not detected in any of the patients including the two cases with coeliac disease.

Table 3 Food antibodies in 48 patients with recurrent aphthae (with two coeliac disease excluded) and two patients with coeliac disease

\begin{tabular}{lll}
\hline & Patients & \\
\cline { 2 - 3 } & 48 & 2 \\
\hline Cereal antigens (precipitin) & 0 & 0 \\
Cow's milk (precipitin) & 2 & 0 \\
Calf's serum (precipitin) & 1 & 0 \\
Chicken's serum (precipitin) & 0 & 0 \\
Cow's milk antibody score & & \\
(passive haemagglutination tests) & & \\
0 & 35 & 0 \\
$1-4$ & 8 & 2 \\
$5-15$ & 5 & 0 \\
$16+$ & 0 & 0 \\
\hline
\end{tabular}

The results of the tests for antibodies to animal protein are shown in Table 3 . In the two patients with coeliac disease, neither had antibodies using the precipitin test but one had a milk antibody score of 4 and the other a score of 1 .

Antibodies to reticulin were demonstrated to be present in one of the 50 patients under investigation, but this individual did not have coeliac disease and had no other haematological abnormality.

The two patients were diagnosed as having coeliac disease from the finding of subtotal villous atrophy in the jejunal biopsy. The remaining 48 were normal and showed no evidence even of partial involvement.

Sufficient jejunal mucosa to carry out enzyme studies was obtained from $94 \%$ of the 50 patients Of these, $24 \%$ had a low value for one or more of the disaccharidases. Unfortunately, enzyme studies were carried out in only one of the two patients with coeliac disease and this had a low value for sucrase.

\section{PROG RESS}

The two patients diagnosed as having coeliac disease were placed on a gluten free diet and their nutritional deficiencies rectified by dietary supplements: folic acid was given to each and ferrous sulphate to the one who also had iron deficiency. In both cases there was a marked improvement with the oral ulceration clearing within one month. These patients have now been followed for two years and neither has experienced any further aphthae.

\section{Discussion}

In this series of 50 'unselected' patients with recurrent aphthae, two $(4 \%)$ were diagnosed as having coeliac disease. This incidence is in agreement with our previous study on patients with recurrent aphthae ${ }^{1}$ and is very much lower than the Birmingham series. ${ }^{2}$ The reason for this discrepancy is not apparent: the source of patients was supposed to be comparable and the diagnosis of recurrent aphthae made using the same clinical criteria.

The two patients with coeliac disease had recurrent aphthae of the minor pattern and no obvious difference existed in the several physical properties of their oral ulcers as compared with the remainder of the group. Neither had any other clinical evidence-for example, glossitis or angular cheilitis-to support the diagnosis of a nutritional deficiency, although one did admit to having alimentary symptoms which were suggestive of malabsorption.

Biochemical evidence of a nutritional deficiency was found in $28 \%$ of the patients but this was not always reflected in the haemoglobin, MCV, or blood film; $10 \%$ of the patients had an abnormal haematological result. Both cases of coeliac disease had clear evidence of folate deficiency and this was reflected in a reduced haemoglobin. However, only one showed an abnormal MCV and blood film, whereas the second patient, who also had iron deficiency, had a normal MCV and film. Other biochemical tests used to detect malabsorption include serum albumin, calcium, and inorganic phosphate but these values were within normal limits for the two coeliac patients.

Patients with coeliac disease often have circulating antibodies to wheat or gluten extracts ${ }^{37}$ as well as to several other dietary antigens. ${ }^{12-14}$ Coeliac patients are able to tolerate foods other than those containing gluten and the current consensus of opinion is that these serum antibodies are related to the increased permeability to macromolecules of the inflamed intestinal mucosa. ${ }^{1,5}{ }^{16}$ This is supported by the fact that patients with oral ulceration from various causes may have a greater incidence of food antibodies. ${ }^{5}$ Testing for antibodies to food antigens appears to provide no useful information in patients with recurrent aphthae and does not identify patients with coeliac disease. Further, when this larger group of patients with recurrent aphthae was examined the incidence of avian antibodies was no greater than that found in controls and the difference in CMA score not as striking.

Reticulin antibodies are found more commonly 
in coeliac disease patients, although we failed to demonstrate these in two patients with coeliac disease in the present study and obtained a positive result for one other patient who was otherwise normal. Therefore it would seem not to be a particularly useful test in the screening of aphthous patients for coeliac disease.

In conclusion, it would appear that the prevalence of coeliac disease is higher in patients with recurrent aphthae than in the general population but this is not nearly as common in this study as previous work indicated. These findings do not support the necessity of routine jejunal biopsies in all patients with aphthae.

In the present series, both patients with coeliac disease were found to have folate deficiency, and the prevalence of folate deficiency in aphthous patients was previously documented.1, 2,17

Nutritional deficiencies not uncommonly exist without changes occurring in the level of haemoglobin, the MCV, or the blood film. Accordingly, it is our opinion that patients presenting with recurrent aphthae should be screened for folate, vitamin B12, and iron deficiency at their initial presentation. Further, if a patient with recurrent aphthae is found to have a depressed whole blood folate then it is reasonable to perform a jejunal biopsy: in the present series two of the eight patients with a low folate concentration were found to have coeliac disease.

We are indebted to the Departments of Haematology and Biochemistry, Western Infirmary, for carrying out the routine haematological and biochemical investigations. We also wish to express our gratitude to the Department of Immunology, Western Infirmary, for estimating the food antibody levels.

\section{References}

${ }^{1}$ Wray D, Ferguson MM, Mason DK, Hutcheon, AW, Dagg JH. Recurrent aphthae: treatment with vi'amin B12, folic acid, and iron. Br MedJ 1975; 2: 490-3.
${ }^{2}$ Ferguson R, Basu MK, Asquith P, Cooke WT. Jejunal mucosal abnormalities in patients with recurrent aphthous ulceration. $\mathrm{Br} \mathrm{Med} J 1976$; 1 : 11-3.

${ }^{3}$ Taylor KB, Thomson DL, Truelove SC, Wright $\mathbf{R}$. An immunological study of cocliac disease and idiopathic steatorrhoea. $\mathrm{Br}$ MedJ 1961 ; 2: 1727-31.

${ }^{4}$ Taylor KB, Truleove SC, Wright R. Serologic reactions to gluten and cow's milk proteins in gastrointestinal disease. Gastroenterology 1964; 46: 99-108.

${ }^{5}$ Thomas HC, Ferguson A, McLennan JG, Mason DK. Food antibodies in oral disease: a study of serum antibodies to food proteins in aphthous ulceration and other oral diseases. J Clin Pathol 1973; 26: 371-4.

${ }^{6}$ Williamson N, Asquith P, Stokes PL, Jowett AW, Cooke WT. Anticonnective tissue and other antitissue 'antibodies' in the sera of patients with coeliac disease compared with the findings in a mixed hospital population. J Clin Pathol 1976; 29: 484-94.

${ }^{7}$ Heiner DC, Lahey ME, Wilson JF, Gerrard JW, Shwachman H, Khaw KT. Precipitins to antigens of wheat and cow's milk in celiac disease. J Pediatr 1962; 61: 813-30.

${ }^{8}$ Beckwith AC, Heiner DC. An immunological study of wheat gluten proteins and derivatives. Arch Biochem 1966; 177: 239-247.

${ }^{9}$ Crosby WH, Kugler HW. Intraluminal biopsy of the small intestine. Am J Dig Dis 1957; 2: 236-41.

${ }^{10}$ Dahlquist A. Method for assay of intestinal disaccharidases. Ann Biochem 1964; 7 : 18-25.

${ }^{11}$ Lee FD. The intestinal mucosa in health and disease. University of Dundee: MD Thesis, 1970.

${ }^{12}$ Alarcón-Segovia D, Herskovic T, Wakim KG, Green PA, Scudamore HH. Presence of circulating antibodies to gluten and milk fractions in patients with nontropical sprue. Am J Med 1964; 36: 485-99.

${ }^{13}$ Rossipal, E. Precipitins to aqueous extract of flour in coeliac disease (Letter). Lancet 1970; 1: 251-2.

${ }^{14}$ Ferguson A, Carswell F. Precipitins to dietary proteins in serum and upper intestinal secretions of coeliac children. Br Med J 1972; 1: 75-7.

${ }^{15}$ Booth CC. Enterocyte in coeliac disease-1. Br Med J 1970; 3: 725-31.

${ }^{16}$ Kenrick KG, Walker-Smith JA. Immunoglobulins and dietary protein antibodies in childhood coeliac disease. Gut 1970; 11 : 635-40.

${ }^{17}$ Wray D, Ferguson MM, Hutcheon WA, Dagg JH. Nutritional deficiencies in recurrent aphthae. $J$ Oral Pathol 1979; 7: 118-23. 